\title{
NÃO TEM NADA DE ERRADO ACONTECENDO
}

\author{
THERE'S NOTHING WRONG GOING ON
}

\section{Gabriel Augusto de Paula Bonfim ${ }^{1}$}

1 Mestrando bolsista CAPES em Artes Visuais, na linha de Processos Artísticos Contemporâneos da Universidade do Estado de Santa Catarina (2019-Atual), sob orientação da Prof. Dra. Sandra Maria Correia Favero. Possui Graduação em Artes Visuais (Licenciatura) pela Universidade Estadual de Londrina (2019). Tem experiência na área de Artes Visuais e Educação. Participou do projeto de iniciação à docência: PIBID - Programa Institucional de Bolsas de Iniciação à Docência (20152017). Atuou como mediador na Divisão de Artes Plásticas - Casa de Cultura UEL (2017-2018). Atualmente participa do grupo de pesquisa Articulações Poéticas (UDESC/CNPq), coordenado por Prof. Dra. Silvana Barbosa Macedo e Prof. Dra. Sandra Maria Correia Favero, investigando processos de caminhadas, coletas e criação de narrativas. Integra a Equipe Editorial da Revista Palíndromo do Programa de Pós-Graduação em Artes Visuais do Centro de Artes da Universidade do Estado de Santa Catarina.

Lattes: http://lattes.cnpq.br/0445222439680724 ORCID: http://orcid.org/0000-0001-5546-4003 E-mail: bonfimgap@gmail.com 


\section{RESUMO}

O presente ensaio visual é composto pelo trabalho intitulado "Não tem nada de errado acontecendo" e encontra-se em permanente processo de criação. Mesclando diferentes modalidades de produção, são realizadas alterações gráficas e conceituais na bandeira do Brasil como forma de denúncia e indignação com o atual período caótico-político-históricosocial do país. As novas bandeiras em questão ganham as ruas de Florianópolis (SC) em forma de lambe-lambe em uma ação performática.

\section{PALAVRAS-CHAVE}

Bandeira do Brasil; Ensaio Visual; Lambe-lambe; Florianópolis.

\section{ABSTRACT}

The present visual essay is composed by the work entitled "There's nothing wrong going on" and is in a permanent process of creation. Merging different forms of production, they are graphic and conceptual changes in the Brazilian flag as a form of denunciation and indignation with the current chaotic-political-historical-social period of the country. The new flags in question gain as the streets of Florianópolis (SC) in the form of wheat-paste in a performance action.

\section{KEYWORDS}

Brazillian flag; Visual essay; Wheat-paste; Florianópolis. 
O objeto de trabalho e experimentação primária é a bandeira do Brasil, adotada oficialmente em 19 de novembro de 1889, é tida por muitos movimentos reacionários como símbolo máximo de patriotismo ao lado de suas cores principais, o verde e o amarelo. A inscrição "Ordem e progresso" foi substituída nessa ação pela frase "Não tem nada de errado acontecendo" e as 27 estrelas que representam os estados e o Distrito Federal foram substituídas por 27 pontos de interrogação.

Busco trabalhar essa angústia política e existencial, que acompanha uma sensação de inércia perante os fatos, manipulando digitalmente a bandeira do Brasil. A arte digital foi impressa em preto e branco em papel sulfite em dimensão A3 plus (329 mm x $483 \mathrm{~mm}$ ). O trabalho ganhou as ruas de Florianópolis (SC) através de lambe-lambes em uma ação performática ao percorrer o centro da cidade, sozinho, desafiando a ordem civil ao realizar todo o processo de colagem e disseminação das bandeiras durante horário comercial.

O trabalho gráfico surge em forma de denúncia irônica e política ao que vem acontecendo no país, como o desmonte da educação pública, das políticas culturais, dos programas sociais, do sistema único de saúde, entre outros. A inscrição "Não tem nada de errado acontecendo" vem como uma afirmação ao lado de dezenas de interrogações.

$\mathrm{Na}$ rua a imagem causa reconhecimento instantâneo, seguido por um estranhamento. As reações foram as mais diversas, de nenhuma até excesso de raiva e retirada das colagens. Foram instaladas no total 11 bandeiras na área central da cidade, nenhuma sobreviveu após dois dias. Pretendo com essas intervenções causar choque contra a anestesia em que nos encontramos. Que a dúvida se instale e que juntos possamos encontrar respostas e maneiras de agir! 
Revista Apotheke

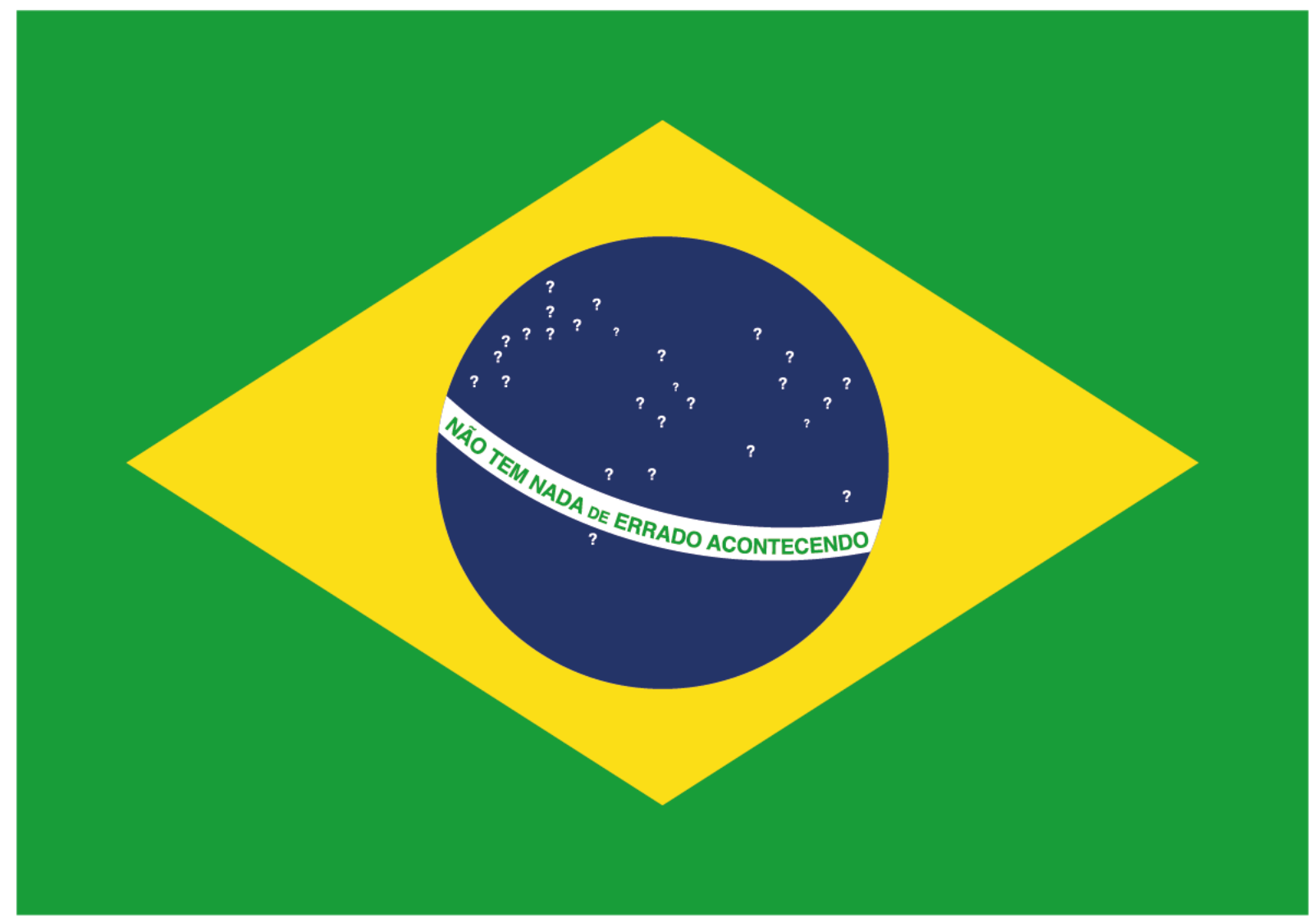




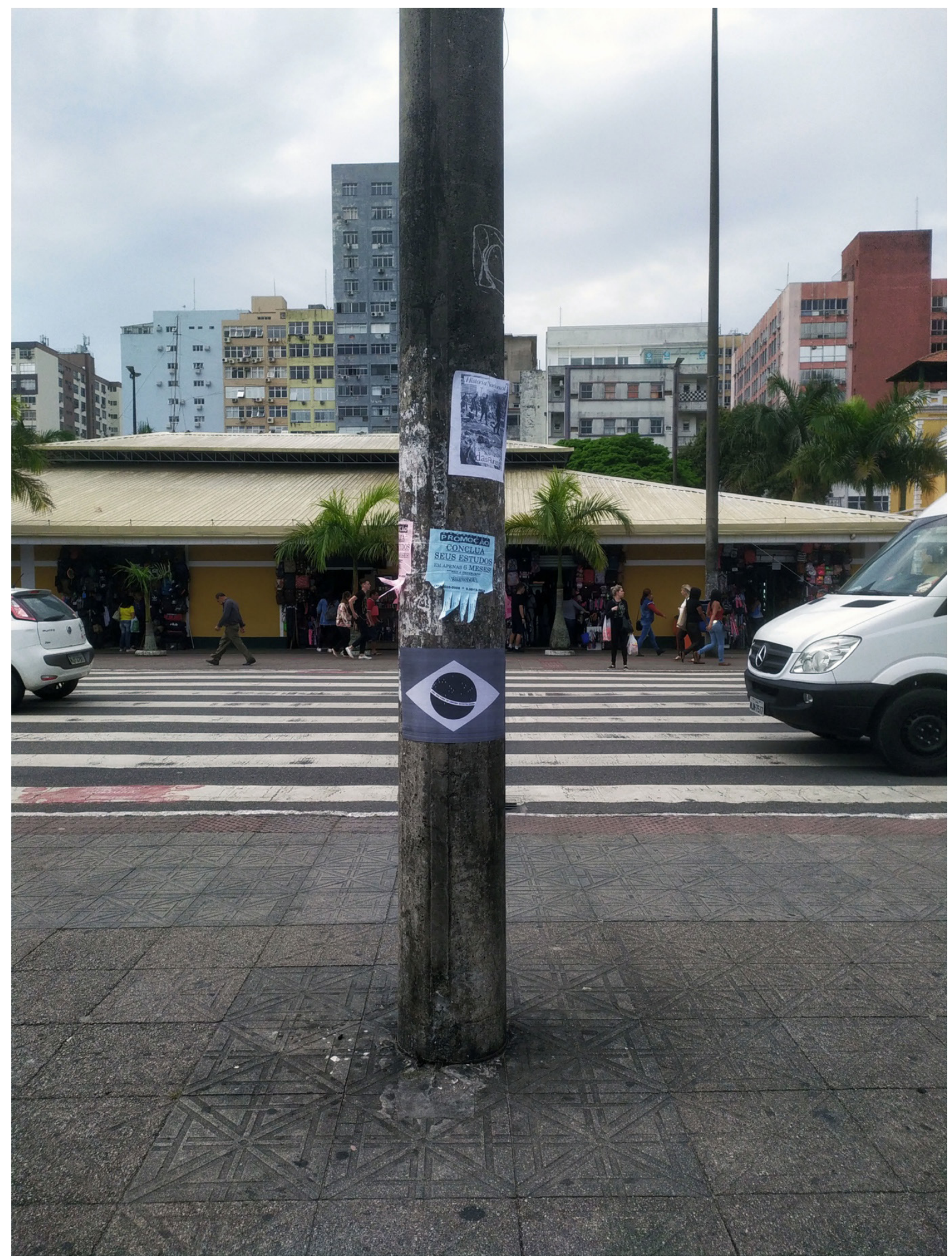




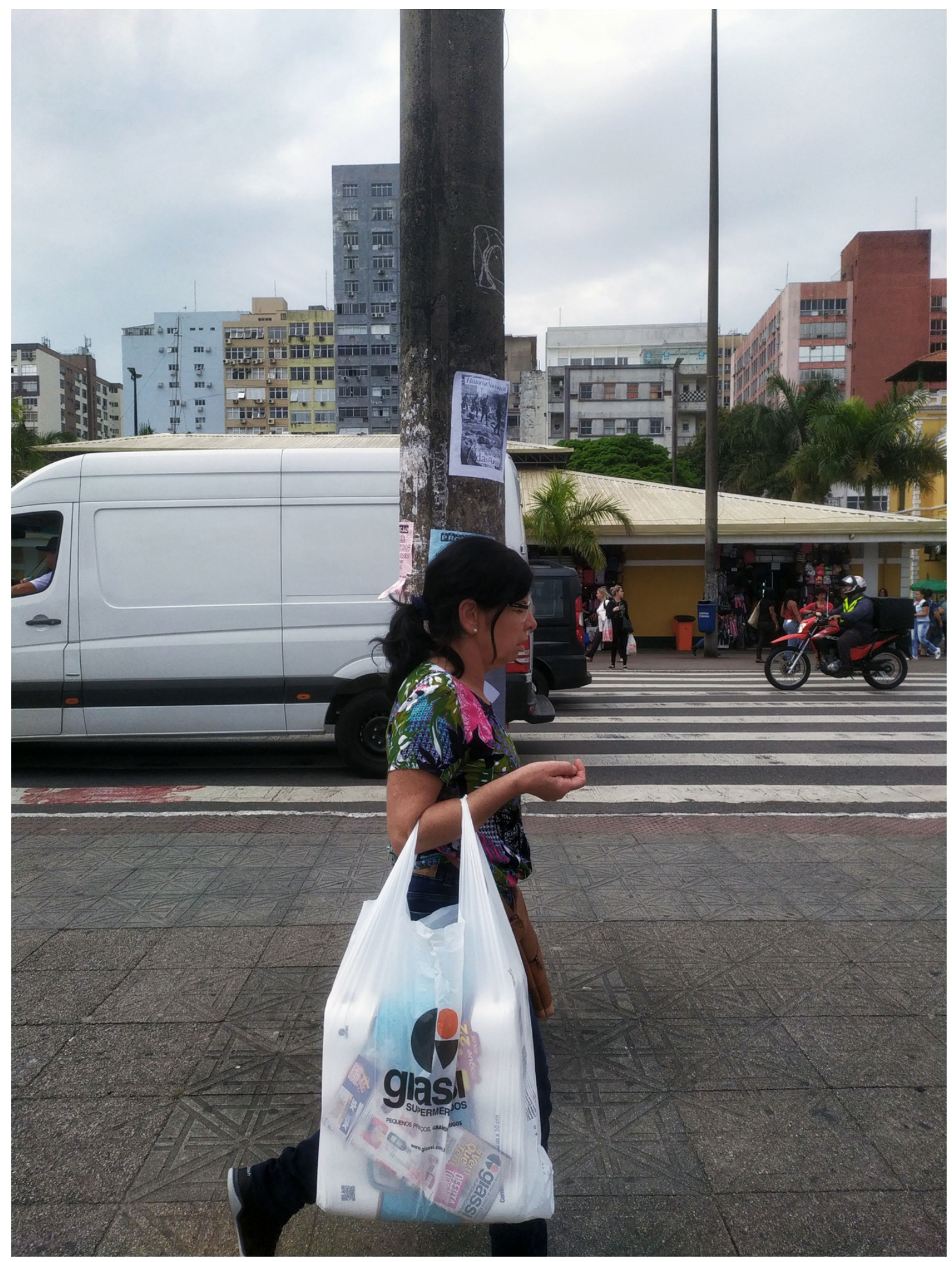




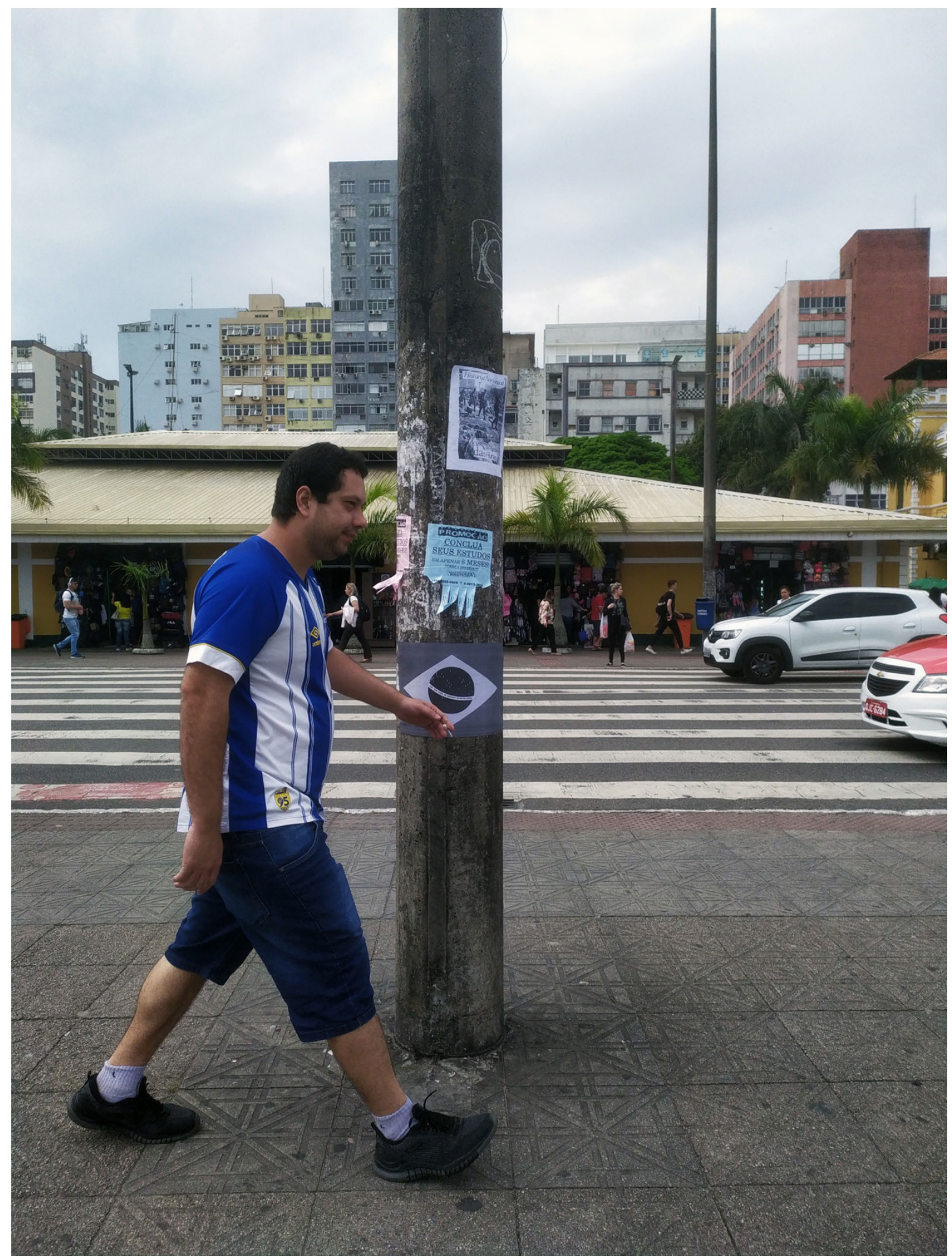




\section{Revista Apotheke}

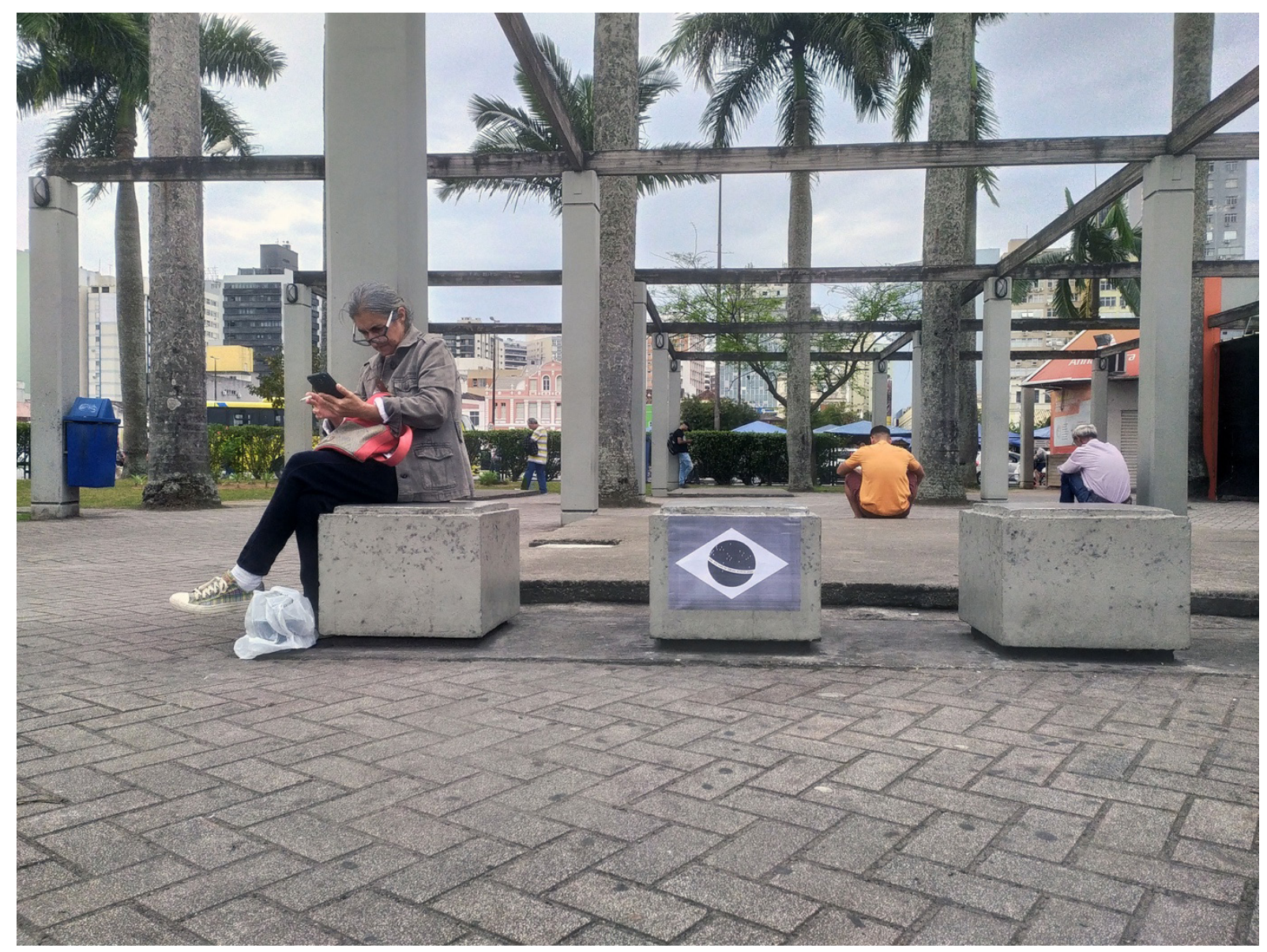




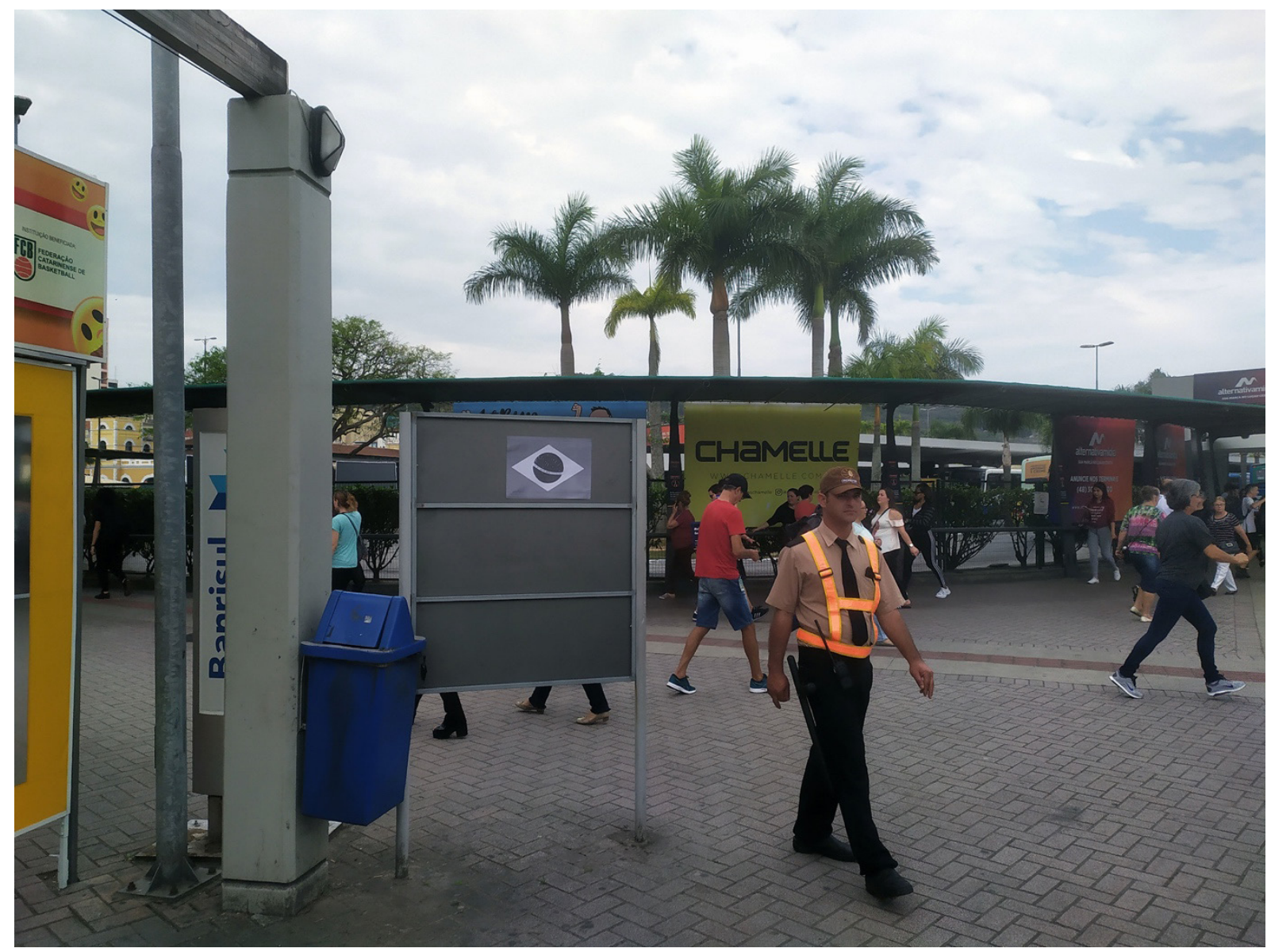




\section{Revista Apotheke}

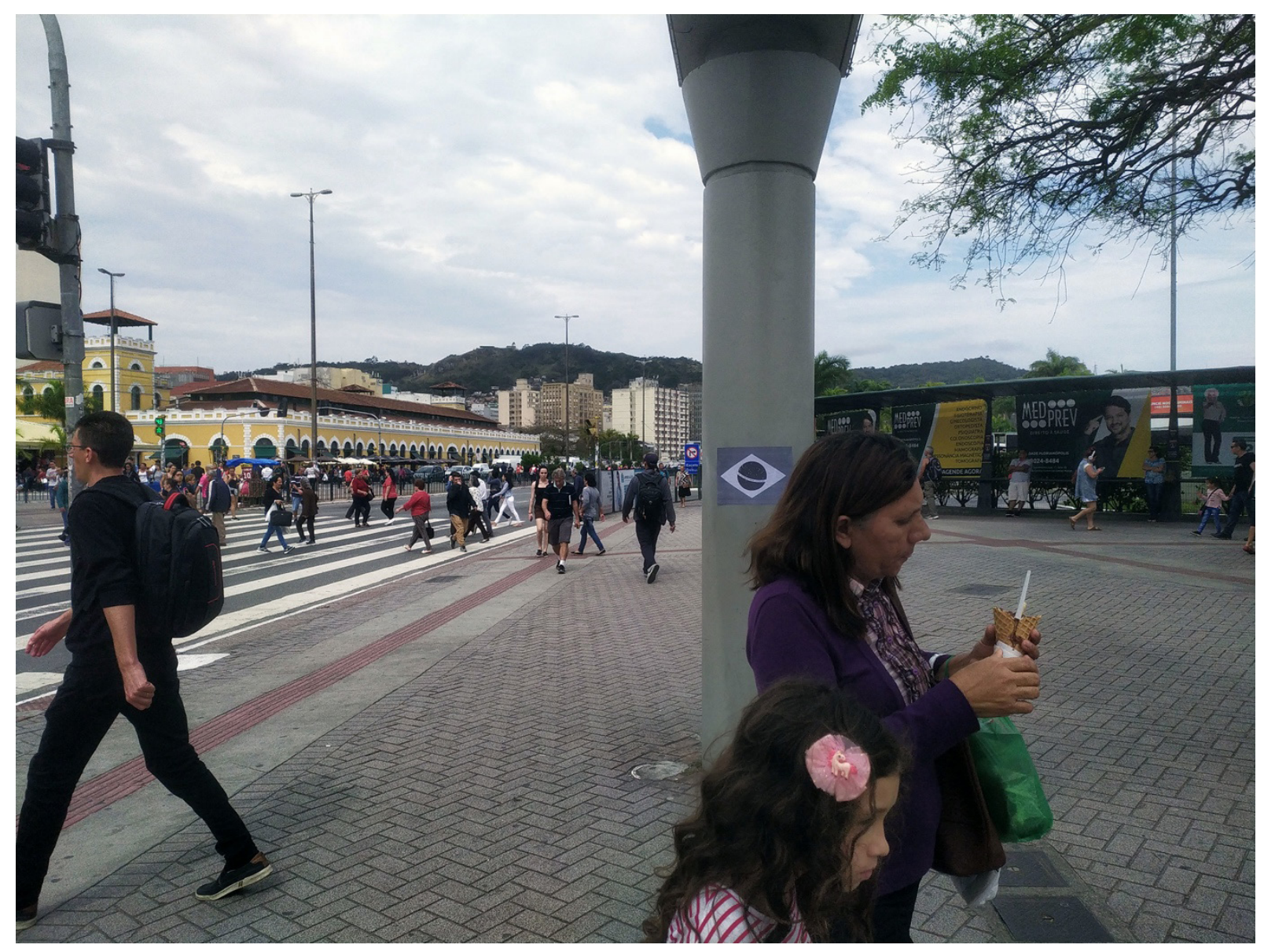



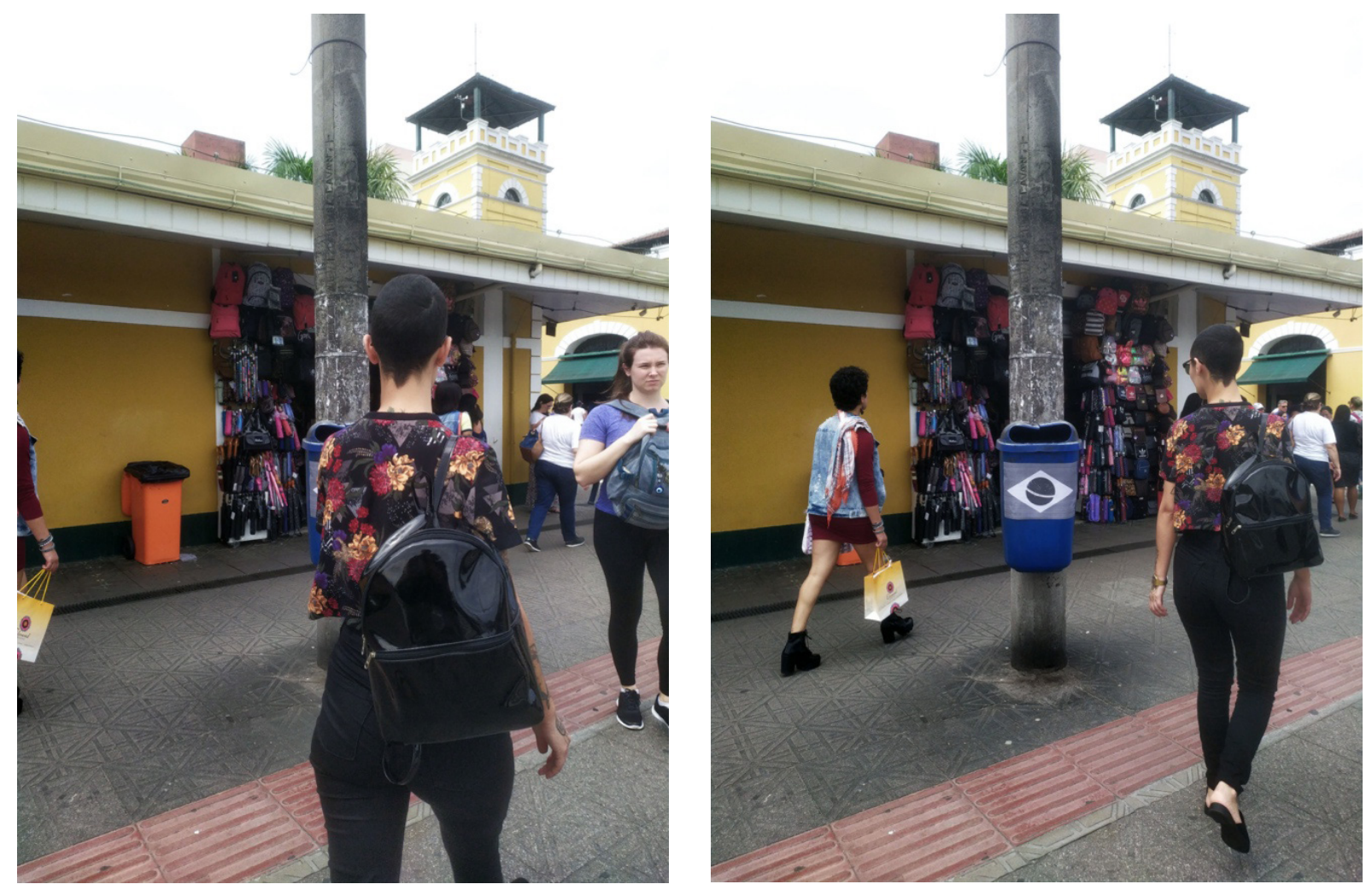
Revista Apotheke

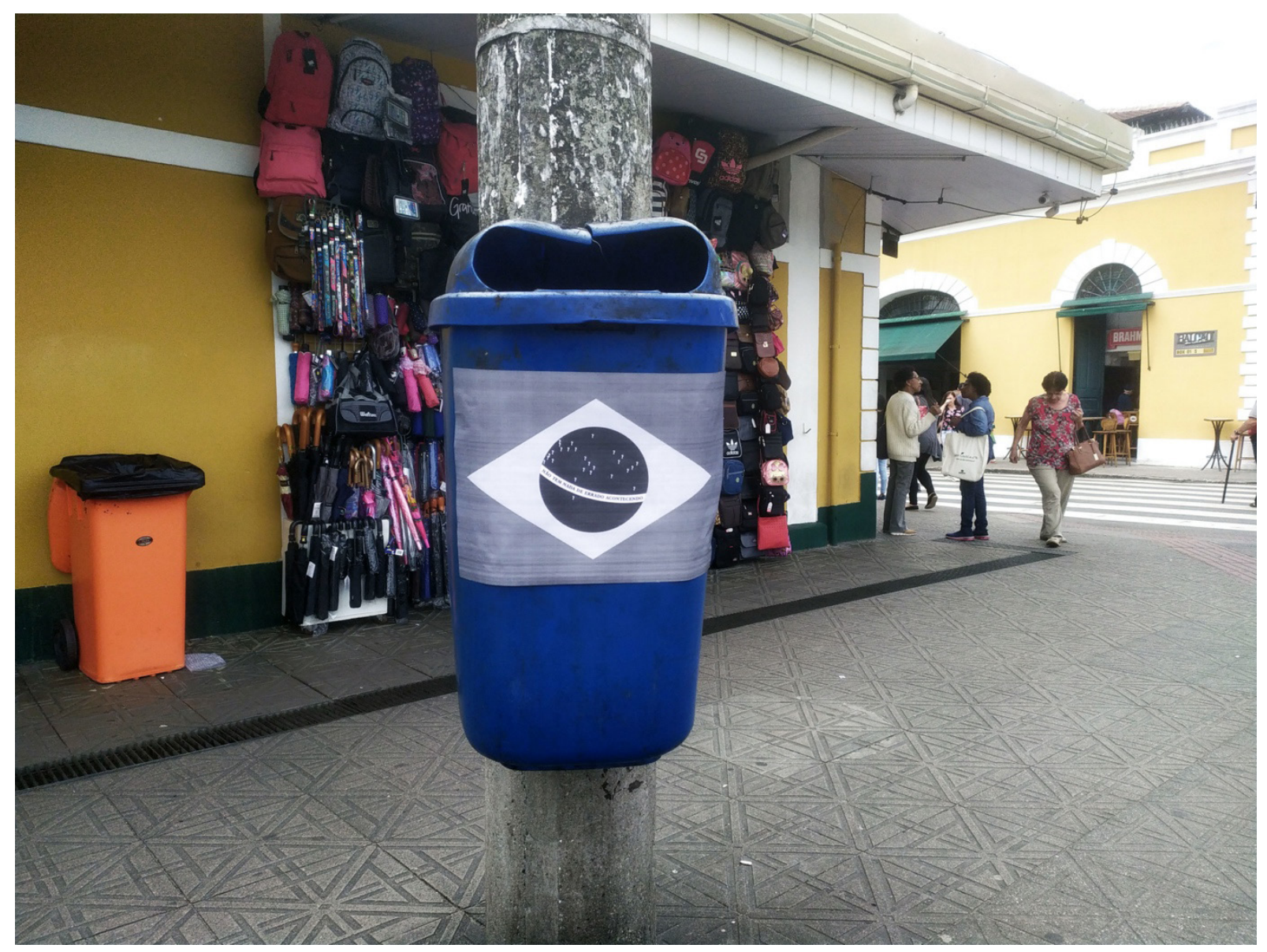




\section{Legendas:}

Fig. 1. Gabriel Bonfim, Não tem nada de errado acontecendo, 2019. Manipulação digital/Lambe-lambe, $32 \times 48 \mathrm{~cm}$.

Fig. 2, 3 e 4. Gabriel Bonfim, Não tem nada de errado acontecendo - Intervenção na Av. Paulo Fontes, 2019. Intervenção urbana, 20 × 30 cm, Florianópolis/SC.

Fig. 5, 6 e 7. Gabriel Bonfim, Não tem nada de errado acontecendo - Intervenção em frente ao Terminal de Integração Central (TICEN), 2019. Intervenção urbana, 20 x $30 \mathrm{~cm}$, Florianópolis/SC.

Fig. 8, 9 e 10. Gabriel Bonfim, Não tem nada de errado acontecendo Intervenção em frente ao Camelódromo Municipal, 2019. Intervenção urbana, 20 × 30 $\mathrm{cm}$, Florianópolis/SC. 